\title{
LXV. On the discovery of an almost perfect skeleton of the Plesiosaurus
}

\author{
Rev. W.D. Conybeare F.R.S. M.G.S.
}

To cite this article: Rev. W.D. Conybeare F.R.S. M.G.S. (1825) LXV. On the discovery of an almost perfect skeleton of the Plesiosaurus, Philosophical Magazine Series 1, 65:326, 412-421, DOI: $10.1080 / 14786442508652889$

To link to this article: http://dx.doi.org/10.1080/14786442508652889

册 Published online: 27 Jul 2009.

Submit your article to this journal

Џ Article views: 2

Q View related articles $\asymp$ 
2. A stone that fell on the 30th of March 1818, at Zaborzyca, and which, not containing globules like the foregoing, could be easily pulverized.

Langier found in 100 parts,

Oxide of iron ............ 4. 45. . . . . . . .

Silica ................. 41.00

Magnesia . . . . . . . . . . . . 14. 140

Sulphur ................. 4.00

Lime.................... 2. 2.00

Nickel .................. 1.00

Alumina .................. 0.75

Chrome................... 0.75

Trace of manganese

$109 \cdot 40$

LXV. On the Discovery of an almost perfect Skeleton of the Plesiosaurus. By the Rev. W. D. Conybeare, F.R.S. M.G.S. *

I

AM highly gratified in being able to lay before the Society an account of an almost perfect skeleton of Plesiosaurust, a new fossil genus, which, from the consideration of several fragments found only in a disjointed state, I felt myself authorised to propound in the year 1821, and which I described in the Geological Transactions for that and the following year. It is through the kind liberality of its possessor, the duke of Buckingham, that this specimen has been placed for a time at the disposal of my friend Professor Buckland, for the purpose of scientific investigation.

At the period of my former communications it was natural and even just that in the minds of many persons interested in such researches, much hesitation should be felt in admitting the conclusions of an observer who was avowedly inexperienced in comparative anatomy; and there might have then appeared reasonable ground for the suspicion that, like the painter in Horace, I had been led to constitute a fictitious animal from the juxtaposition of incongruous members, referable in truth to different species. But the magnificent specimen recently discovered at Lyme has confirmed the justice of my former conclusions in every essential point connected with the organization of the skeleton.

The only material error which I have to correct relates to the bones which I supposed to be the radius and ulna: but

* From the Geological Transactions, New Series, vol. i.

† Some philological objections having been made to the composition of the word Plesiosaurus, $I$ beg to state that it is formed on the very same

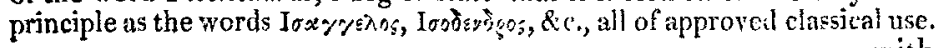
with 
with regard to the other parts of the skeleton, in assigning to the same animal the heads and vertebræ, which had at that time never been found in connexion, and whose actual relation was therefore regarded by many as equivocal, in indicating the order and place of the several kinds of vertebræ, and in tracing the osteology of the humero-sternal parts, my opinions have received full confirmation. In the attempted restoration of the paddle also (though professedly given only on conjecture) a very considerable approximation to the true structure of the part will be found, considering the very imperfect materials afforded by the fragments which had then been obtained.

But in addition to these particulars, which in all their material features were correctly stated, the specimen now exhibited presents others of a most novel and interesting character, not to have been anticipated previously to the discovery of a skeleton, the whole exterior portion of whose vertebral column was perfect. I particularly allude to the neck, which is fully equal in length to the body and tail united; and which surpassing in the number of its vertebræ that of the longestnecked birds, even the swan, deviates from the laws which were heretofore regarded as universal in quadrupedal animals, and the cetacea. I mention this circumstance thus early, as forming the most prominent and interesting feature of the recent discovery, and that which in effect renders this animal one of the most curious and important additions which geology has yet made to comparative anatomy.

I now proceed to the details in the usual order.

Head. -The present specimen, and another of this part only; in possession of MissPhilpot, confirm the restoration attempted from the distorted head figured in Plate XIX. of the first volume of the second series of the Geological Transactions; and the latter extends our knowledge by exhibiting distinctly the occipital portion. We now also learn for the first time, that the head of this animal was remarkably small, forming less than the thirteenth part of the total length of the skeleton; while in the Ichthyosaurus its proportion is one-fourth. This proportional smalness of the head, and therefore of the teeth, must have rendered it a very unequal combatant against the latter animal; but the structure of its neck may perhaps be considered as a conpensating provision, supplying it with the means of security and of catching its prey.

Vertebra.-The distinctions between the cervical and caudal vertebræ have been fully and correctly stated in my former communications; but I had not at that time observed more than twelve of the cervical, whereas the present specimen exhibits about thirty-five, or, including the anterior dor- 


\section{The Rev. W. D. Conybeare on the Discovery}

sal, which were placed before the humerus, and bore only five ribs, forty-one*. This great increase of the number of joints in the neck is the more remarkable from the rigour with which nature appears, in most cases, to have enforced the law of a very limited number. In all quadrupedal animals, in all the mammalia (excepting only the tridactyle sloths, which have nine) the series is exactly seven; and so strict is the adherence to this rule, that even the short and stiff neck of the whale; and the long and flexible neck of the cameleopard, are formed out of the same elementary number; the vertebræ in the former instance being extremely thin and anchylosed together, and in the latter greatly elongated. Reptiles possess only from three to eight cervical vertebræ; birds, approaching in this more nearly to the present species, but still falling greatly short of $\mathrm{it}$, have from nine to twenty-threet, the number being the greatest in the swan. The Ichthyosaurus appears to have possessed about eighteen cervical vertebræ. In fishes the ribs commence almost immediately behind the head.

The views of Geoffroy de St. Hilaire, - that nature in the organization of the animal frame has caused the sternal portion to shift its position along the vertebral column,- - seem to derive an important corroboration from the structure of this animal: but it is remarkable, that whereas the sternum holds a mean position in quadrupeds, and is thrown forward in fishes and backwards in birds, yet its position in this instance assimilates the Plesiosaurus less to fishes, though destined to move in the same element $f$, than to birds, and exhibits at the same time a very wide departure from the type of the Saurian tribe. Al-

* It is difficult to assign the exact demarcation between these subdivisions of the column; because the inferior lateral or hatchet-shaped processes of the cervical vertebræ (which in this animal greatly resemble those of the crocodile) gradually become elongated, and assume almost insensibly the character of false ribs.

+ The sparrow is said to possess only nine cervical vertebræ (Cuvier's Anatomie Comp.). In aquatic birds the length of the neck, as well as the number of the cervical vertebræ, generally exceeds what we observe in the land birds, this construction enabling the former to procure sustenance in their own peculiar element.

$\ddagger$ The Testudo longicollis, an inhabitant of fresh-water and a native of Australasia (see Shaw's Zoology, vol. iii. p. 62), is the most remarkable among the tortoises for length of neck; and the figure of this animal in the work referred to will serve to illustrate what in the Plesiosaurus must have been the external appearance of this part when covered with integuments. It would be very desirable to ascertain, from an examination of the skeleton, whether this species has more than the usual number of cervical vertebræ. Most of the tortoise tribe have the power of extending their necks considerably, especially the Testudo ferox (see Shaw. vol. iii. p. 65), whose neck, when exserted, is equal in length to the shell. By darting out this it is enabled to make even birds its prey. 
though the number of the cervical vertebræ is thus unexampled, yet the length of the neck is nearly rivalled by another of the reptile class, namely, the land tortoise. The length is in this case concealed by the anterior extension of the shell; the neck, however, notwithstanding its elongation, has only eight vertebræ. The general proportions of the tortoise, its length of neck, shortness of tail, and the smallness of its head, are in some degree analogous to what we observe in the Plesiosaurus; but the structure of the head and teeth of the latter, and its want of shell, entirely negative the idea of its being intimately allied to the tortoise, and decidedly connect it with the Saurian order.

It will be necessary to subjoin a few words on the inferior hatchet-shaped processes which may be seen depending on either side from the lower part of the cervical vertebræ. Most animals present traces of these processes; they are particularly prominent in many of the long-necked quadrupeds, and in birds project into a long styloid branch; a rudiment of these may be observed in man, but I am not aware that any particular name has been assigned to them*. They have been sometimes confounded with the transverse processes, to which they often form a wing-like appendage. These processes are important, as serving to determine the number of the cervical vertebræ, and as affording very close analogies between the Plesiosaurus and the crocodile; in both these animals these inferior hatchet-shaped processes ure exactly similar in figure, and form separate pieces attached to the body of the vertebræ by a double stem. In the figures given of the cervical vertebræ in my former memoir, this stem alone, and the double suture which receives it, could, from the imperfect state of the specimens, be represented; but I then expressed my conviction that the structure resembled that of the same part in the crocodile, and my conjecture is now verified.

The thirty-five anterior vertebræ of the Plesiosaurus exhibit these processes distinctly characterized, and are therefore beyond all doubt cervical; in the six following the processes become lengthened, and gradually lose their hatchet-shaped extremity, assuming rather the form of false ribs, and should therefore perhaps be classed as anterior dorsal; but the whole forty-one are clearly placed before the pectoral extremities. In the crocodile there are seven cervical vertebræ with hatchet-

* Dr. Macartney, in his Anatorny of Birds, says, "The transverse processes of the vertebræ of the middle of the neck spread forwards, and send down a styloid process of some length." - " The anterior styloid processes are but little observable in the rapacious and passerine tribes, the parrot, \&c. ; but they are very marked in the long-necked birds."

shaped 
shaped processes, and three anterior dorsal with false ribs before the humero-sternal portion. Since flexibility must evidently be the end of this great multiplication of the joints, it may perhaps excite surprise that the joints, instead of articulating as in birds by cylindrical surfaces, should have their contiguous faces nearly flat, which must have allowed a less freedom of motion between each vertebra; but it may be answered, that the increased number of the joints compensated for the stiffness of each.

Dorsal Vertebra.-I have nothing to add to my former remarks on this part of the column: the greater part of these, in the splendid specimen from Lyme, are removed from their place, and are scattered over the mass of shale in which they are imbedded. In consequence of this accident, we are admitted to a full view of the ribs and sterno-costal arcs and pelvis, which remain undisturbed. Fourteen large ribs may be counted; and twenty-one dorsal or lumbar vertebræ appear dispersed, though their exact original number cannot be ascertained. 'The last of these lies over the pubis, and has, close to it, a short false rib.

Twenty-three caudal vertebræ are remaining; and as about three of the extreme ones appear to be wanting, we may probably assume this part at about twenty-six joints: the whole vertebral column then will number about 90 joints; viz. 35 cervical, 6 anterior dorsal, 21 dorsal and lumbar, 2 sacral, and about 26 caudal. The proportions of the whole of these parts will stand nearly thus: taking the head as 1 , the neck will be as 5 , the body as 4 , and the tail as 3 , the total length being, as was before remarked, thirteen times that of the head.

The chevron bones beneath the tail are finely exhibited; but this part, having been fully described in my former papers, suggests no new remarks, excepting that its shortness must have prevented its being used, as in fishes, as an instrument of impulsion in a forward direction, and that it was therefore probably employed only as a rudder to steer the animal by horizontal flexure, or by a sudden vertical stroke to elevate or depress it while swimming through the water.

The anterior sternal portion is greatly concealed by the vertebræ and ribs lying over it; these might be carefully removed and replaced, and the structure of this important part ascertained. From several imperfect specimens which I have examined, it appears to have been complicated in its structure, and nearly to have resembled that of the Tupinambis.

The posterior part of the sternum consists of a central bony arc, crescent $\rightarrow$ baped, and swelling in the middle; to its horns are applied two sterno-costal branches, which appear as usual 
to have been connected with the extremities of the ribs by cartilages: the nice adaptation of these parts is beautifully displayed in the specimen.

The pelvis is finely displayed, and resembles the usual type of this part in reptiles, of which the turtle perhaps affords the best example for comparison with the fossil: the ilium is reduced to a long and slender bone, which might, if seen detached, be mistaken for the os pubis; that of several species of turtle is exactly similar. The ischium is like that of most reptiles; and the pubis, as is also common in this class, is so greatly dilated as to be liable to be mistaken for the ilium if found separately. All these parts are very nearly in situ, and the manner in which they unite to form the acetabular socket is easily perceived; the oval formation between the ischium and pubis is also quite distinct.

Humero-sternal parts. - In one of the specimens of Saurian remains, presented by Colonel Birch to the Museum at Oxford, the humero-sternal, or rather humero-clavicular, parts on one side of the animal are almost perfect. It is only at the extremities of the clavicle and scapula that the bones themselves are preserved; but the intermediate parts, though removed, have left an impression of their lower surface. Enough remains to enable us with certainty to identify these bones with more perfect specimens of the same, which have been found in a detached state. It is from these materials that $I$ have effected the restoration of the humero-clavicular parts represented in Plate III. fig. 2.

The humero-clavicular parts consist, as in birds, and as in the lizard and some other reptiles, 1st, of coracoid bones separated from the scapula; $2 \mathrm{~d}$, of a small scapula; and $3 \mathrm{~d}$, of clavicles.

The coracoid bones in the specimen at Oxford are greatly elongated, in comparison of those represented in my first memoir, though resembling the latter in every other particular. I hesitate to consider this difference as specific, because the shorter coracoids evidently belonged to a much younger individual than the longer, as appears from the circumstance of these and other bones, which have become anchylosed in the latter case, remaining distinct in the former. I ought, however, to add, that a third fragment of this part, which certainly belonged to a large adult, and exhibits the anterior portion of the two coracoids adhering to a series of anterior dorsal vertebræ, agrees in form most nearly with the shorter specimen. The specimen belonging to the duke of Buckingham possessed the long coracoids, traces of them being very evident beneath all the anterior ribs. Should it appear on further

Vol. 65. No. 326. June 1825.

$3 \mathrm{G}$ inquiry 


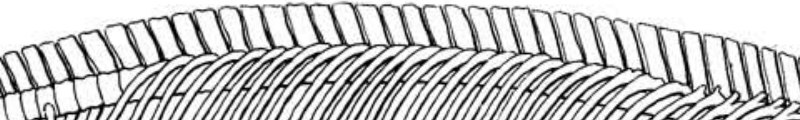

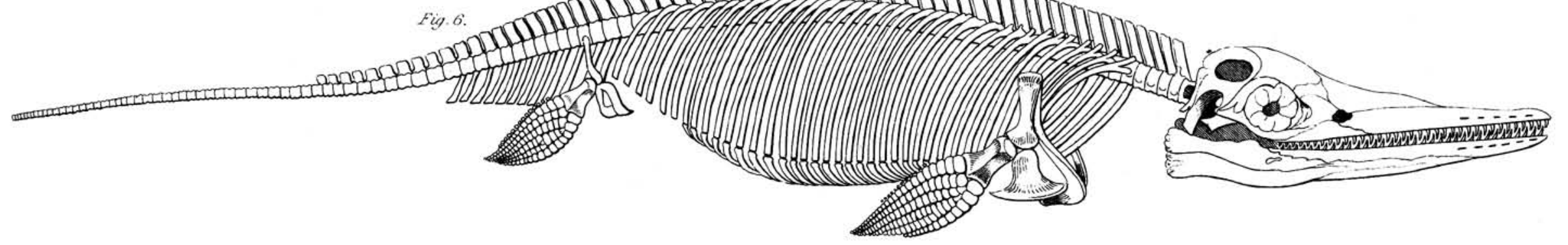

Fig. Z.

Plesiosaurus Dolichodeirus Fì.I

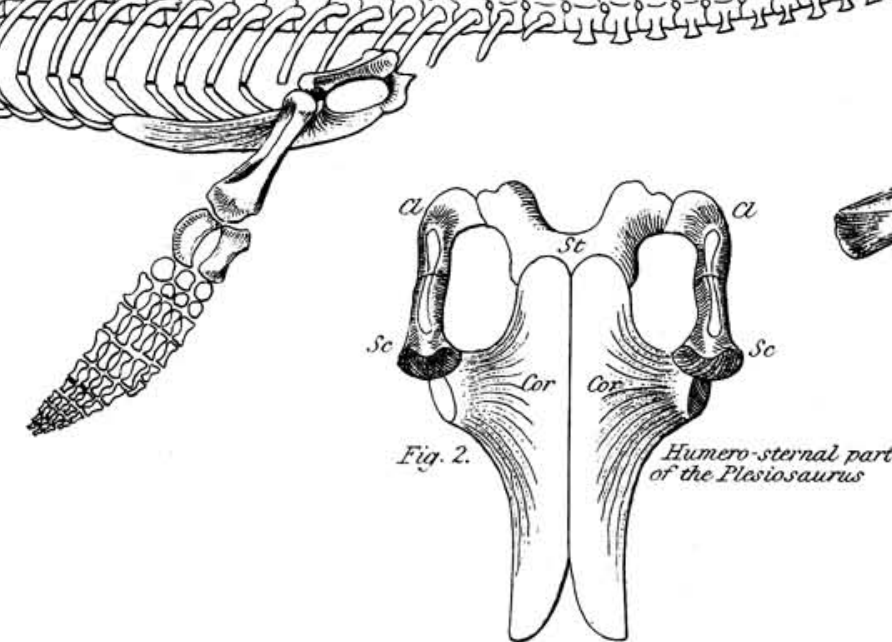

Pelvis of the Flcsiosaures
Humero-sternal part of the Ichchyosaurus
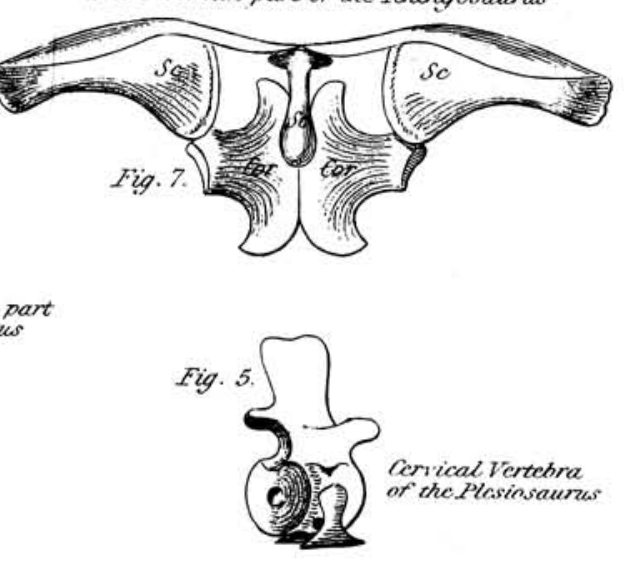

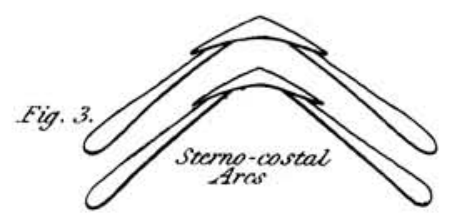


inquiry that there were two species, we learn from the specimens already procured that the specific distinctions were very slight, that noticed in the coracoids being in fact the only one that I have been able to detect after a careful collation of the most important parts in all the specimens that I have examined.

The scapula bas been correctly represented in my first memoir; but the humerus, which I had there figured from the only specimen in which I had seen those two parts together (and which, having belonged to the late Mr. Catcott, is preserved in the public library at Bristol), in consequence of an accidental dislocation is exhibited in an inverted position. The clavicles consist of two transverse and one central piece. The former are the clavicles, strictly speaking; the latter may, perhaps, more properly be referred to the sternum. The corresponding part or furcular in the Ichthyosaurus also consists of two transverse and one central piece, as does that of the Ornithorynchus, when young, as has been noticed by Mr. Clift; but the central piece in these animals forms merely a short stem or handle (as it may be called) connected with the transverse clavicles, whereas in the Plesiosaurus it is considerably more developed. The general analogies between these parts in the reptile tribe, in the Ornithorynchus, and in birds, have been ably pointed out by Geoffroy St. Hilaire and Cuvier.

In the plate containing a restoration of the Plesiosaurus, (Plate III.) I have added, for the purpose of comparison, a sketch of this part in the Ichthyosaurus. That published in the Philosophical Transactions does not exhibit the tripartite division of the furcula, and erroneously makes its branches curve considerably too much upwards. The present outline is founded on three very perfect specimens, which entirely agree with one another in the parts here represented, and leave no doubt of their actual form.

Extremities.-The humerus articulates immediately with the bones, which in my preceding descriptions $I$ had considered as the first row of the carpus; which contains only two instead of the three pieces placed together in the conjectural restoration. I have again to acknowledge the error into which 1 have been led in the insertion of a supposed radius and ulna between these parts; for the two pieces which form the first row formerly ascribed to the carpus, now appear to be the true representatives of the radius and ulna, though greatly differing in form from the usual type of those parts.

The conjectural restoration of the paddles would very nearly apply to the posterior paddles as exhibited in this specimen, by abstracting the outer bone from this supposed carpus, and 
removing also the exterior and circular bones from the edges of the paddle as there drawn. I was led to introduce these exterior paddle-bones from the specimen represented, fig. 1, Pl. XLII. Geological Transactions, vol. v., in which they are so placed; but I have subsequently retracted this view, having learnt that when the specimen referred to was found, the bones in question were loose, and had been subsequently glued into their present situation, in consequence of a conjecture of the proprietor. I mention this circumstance lest any real inconsistency should be supposed to exist between that specimen and the more perfect and illustrative remains now discovered.

All the paddles are composed of two rows of nearly circular or discoidal bones, representing the carpus and tarsus, and of five digitated series, representing the metacarpal or metatarsal and phalangic bones, the distinction between these being inappreciable, though we may of course, in conformity to the usual nomenclature, term the first phalangic bones metacarpal, \&c., if so inclined. The first or anterior digit on each paddle has four phalanges; the last, seven. These are evidently complete in the specimen. The whole five digits stand as follows :

Anterior paddle.

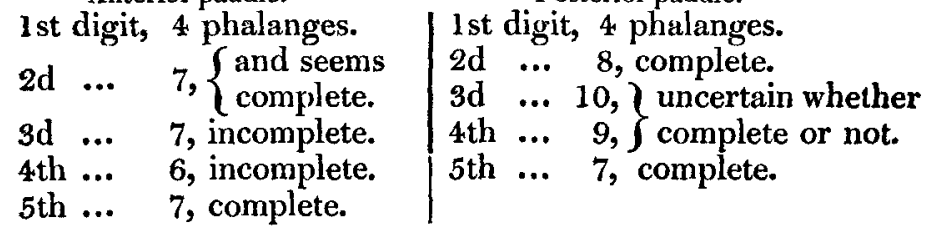

This great multiplication of joints in the phalangic series strongly distinguishes this animal from all known quadrupeds. In the whole class of mammalia (some cetacea only excepted) the number of phalanges in the perfect and longest digits is restricted to three; it is the same in most of the reptiles; but some Saurians, e.g. the crocodile, exceed this number by one joint: birds also have only five phalanges.

A majority of the cetacea appear to possess only three phalanges, but in some species the number is increased; and the Rorqual (a species of Balcena) and the Delphinus Delphis present as many as seven (see Cuvier's Ossemens Fossiles, tom. v., and Camper's Cetacea, Pl. 44.), the nearest approximation to the number in the Plesiosaurus, though less than the number in the posterior paddle of that animal by two joints.

Although all the other analogies of the fossil animal refer it to a class widely differing from the cetacea, it is yet interesting to observe that in these instances, taken from beings of distinct general organization, the use for which nature in- 
tended this part, viz. natation, being the same, a similar modification has been superinduced on the usual structure of quadrupedal extremities.

On the whole, this part in the Plesiosaurus presents a link between the usual structure and the still more complicated organization of the paddle in the Ichthyosaurus; the phalanges are flattened as in the turtle, and other animals destined for natation, and were doubtless in like manner covered by a common integument, and thus converted into a species of fins.

I shall conclude with some more general remarks.-In its motion this animal must have resembled the turtle more than any other; and the turtle also, as was before remarked, could we divest it of its shelly case, would present some slight approach in its general proportions to the Plesiosaurus.

I shall leave to others more conversant than myself with the analogies of comparative anatomy, the inferences to which those particulars may learl concerning the habits of this singular animal.

That it was aquatic is evident from the form of its paddles; that it was marine is almost equally so, from the remains with which it is universally associated; that it may have occasionally visited the shore, the resemblance of its extremities to those of the turtle may lead us to conjecture; its motion, however, must have been very awkward on land; its long neck must have impeded its progress through the water, presenting a striking contrast to the organization which so admirably fits the Ichthyosaurus to cut through the waves. May it not, therefore, be concluded (since, in addition to these circumstances, its respiration must have required frequent access of air), that it swam upon or near the surface, arching back its long neck like the swan, and occasionally darting it down at the fish which happened to float within its reach?

It may, perhaps, have lurked in shoal water along the coast, concealed among the sea-weed, and raising its nostrils to a level with the surface from a considerable depth, may have found a secure retreat from the assanlts of dangerous enemies; while the length and flexibility of its neck may have compensated for the want of strength in its jaws and its incapacity for swift motion through the water, by the suddenness and agility of the attack which they enabled it to make on every animal fitted for its prey whieh came within its extensive sweep.

The name I have originally given to this animal, Plesiosaurus (approximate to the Saurians), may appear rather vague in this stage of our knowledge, and an appellation derived from its peculiar length of neck might be preferred; but for the pre- 
sent I shall retain the old generic name, adding for specific distinction the well-known Homeric epithet Dolichodeirus, as characterizing the most striking peculiarity of its osteology. I am the rather induced to follow this course because I think it very probable, from specimens which I have examined, that species of Plesiosaurus with shorter necks exist in other strata. I have already figured a column, belonging to an animal of this genus, in which the proportions of the Plesiosaurus Dolichodeirus are inverted, the vertebræ of the neck being considerably thinner than those of the body. Professor Buckland has since obtained from Market Raisin, large fragments of the skeleton of the species to which that vertebral column must have belonged; its remains are common in the Kimmeridge or Oaktree clay. From its enormous size I shall provisionally indicate this species as Plesiosaurus giganteus, and I hope hereafter (in union with my friend) to submit drawings and a description of those remains to the Society.

With reference to the elucidation of all these questions, I cannot but congratulate the scientific public that the discovery of this animal has been made at the very moment when the illustrious Cuvier is engaged in, and on the eve of publishing, his researches on the fossil ovipara: from him the subject will derive all that lucid order which he never has yet failed to introduce into the most obscure and intricate departments of comparative anatomy.

LXVI. Menstruum for Biting-in on Steel Plates. By Mr. Eduund Turrell, of Clarendon-street, Somerstoron*.

THE demand that has taken place for engravings upon decarbonized steel plates, on account of their great durability when compared with copper plates, has caused many eminent artists to employ their talents upon that peculiar preparation of metal; and many beantiful specimens of line-engraving have been produced, capable of yielding proofs or prints to an extent unknown before the invention and application of that peculiar preparation of steel, which was first, I believe, made known to the world by Mr. Perkins, who has made use of it very extensively in his bank-note manufactory in the United States of America, and more recently in London.

If the execution of a fine engraving upon such prepared or decarbonized steel had depended entirely upon the graving tool, the principal difficulty that presents itself would be the

- From the Transactions of the Society of Arts.--The large gold medal was presented to Mr. Turrell for this communication. 